\title{
Simplified Fiber Beam-column Element Considering local Shear Effect
}

\author{
Ziping Zhu, Xue Zhang \\ Dalian University of Technology \\ 116000, Dalian, China \\ zpzhu@mail.dlut.edu.cn; xuezhang@dlut.edu.cn
}

\section{Extended Abstract}

Accurate and efficient beam-column elements are of great importance in predicting nonlinear response of reinforced concrete $(\mathrm{RC})$ frame structures under seismic loads. The fiber-based model could accurately predict flexural hysteretic response of RC members by using uniaxial stress-strain relations to model concrete and reinforcements, respectively [1,2]. However, the fiber-based model fails to consider the shear deformation due to the plane-sections-remain-plane assumption, which limits its application in shear-critical members, such as short columns and coupling beams.

So far, the shear response of fiber-based beam-column element was considered by two ways. First, the Timoshenko beam theory was applied along with fiber model to include the degree of freedom (DoF) of shear at the sectional level. In this way the multi-axial constitution model of concrete was generally required to consider the shearflexure interaction [3-6], which limits the computational feasibility and efficiency of the models. Another approach was to consider shear response by introducing a spring at the end of the beam-column member. In this case the flexural behavior of RC member was simulated by using fiber model, and the shear was modelled by elongation of the spring in transverse direction. As a result, the shear and flexural behaviors can be modelled separately with a higher efficiency compared to the former approach. It should be noted that the empirical force-deformation relations required by shear spring were generally obtained from global hysteresis tests. It means that the component-end lumped spring is incapable of modelling shear response of RC members which is sensitive to local shear deformation accurately [710].

Therefore, this study presents a new beam-column element to consider local shear effect of member with reasonable numerical accuracy and computational efficiency. The flexure and axial response of the proposed element is modelled by traditional fiber model. The shear deformation is decomposed from the axial and flexural deformations in the element. The total transverse displacement of the element is induced by flexure and shear. The transverse displacement caused by flexure can be determined by element length and corresponding rotation, thus shear deformation is the subtraction of calculated flexure transverse displacement from total transverse displacement. The shear deformation in any segment of element can be calculated by this method. The shear deformation of the element can be obtained by summing the shear deformation of these segments. Finally the element stiffness matrix is assembled as the sum of shear and flexure stiffness using the principle of virtual work. It can be seen above that the local shear effect of the member can be considered by the proposed element, resulting in a more accurate prediction compared with component-end lumped spring.

\section{References}

[1] E. Spacone, F. C. Filippou, and F. F. Taucer, "Fibre beam-column model for non-linear analysis of R/C frames .2. Applications," Earthquake Engineering \& Structural Dynamics, vol. 25, no. 7, pp. 727-742, Jul 1996.

[2] E. Spacone, F. C. Filippou, and F. F. Taucer, "Fibre beam-column model for non-linear analysis of R/C frames .1. Formulation," Earthquake Engineering \& Structural Dynamics, vol. 25, no. 7, pp. 711-725, Jul 1996.

[3] D.-C. Feng and J. Xu, "An efficient fiber beam-column element considering flexure-shear interaction and anchorage bond-slip effect for cyclic analysis of RC structures," Bulletin of Earthquake Engineering, vol. 16, no. 11, pp. 5425-5452, Nov 2018.

[4] A. Kagermanov and P. Ceresa, "3D Fiber-Based Frame Element with Multiaxial Stress Interaction for RC Structures," Advances in Civil Engineering, 2018. 
[5] M. Petrangeli, "Fiber element for cyclic bending and shear of RC structures. II: Verification," Journal of Engineering Mechanics-Asce, vol. 125, no. 9, pp. 1002-1009, Sep 1999.

[6] M. Petrangeli, P. E. Pinto, and V. Ciampi, "Fiber element for cyclic bending and shear of RC structures. I: Theory," Journal of Engineering Mechanics-Asce, vol. 125, no. 9, pp. 994-1001, Sep 1999.

[7] A. D'Ambrisi and F. C. Filippou, "Modeling of cyclic shear behavior in RC members," Journal of Structural Engineering-Asce, vol. 125, no. 10, pp. 1143-1150, Oct 1999.

[8] R. Ding, M.-X. Tao, J.-G. Nie, and Y. L. Mo, "Shear Deformation and Sliding-Based Fiber Beam-Column Model for Seismic Analysis of Reinforced Concrete Coupling Beams," Journal of Structural Engineering, vol. 142, no. 7, Jul 2016, Art no. 04016032.

[9] M. S. Lodhi and H. Sezen, "Estimation of monotonic behavior of reinforced concrete columns considering shear-flexure-axial load interaction," Earthquake Engineering \& Structural Dynamics, vol. 41, no. 15, pp. 2159-2175, Dec 2012.

[10] A. Marini and E. Spacone, "Analysis of reinforced concrete elements including shear effects," Aci Structural Journal, vol. 103, no. 5, pp. 645-655, Sep-Oct 2006. 